DOI: $10.21701 /$ bolgeomin.130.4.008

\title{
El manejo del agua en las cuencas de alta montaña del Parque Nacional de Sierra Nevada (Sur de España). Un ejemplo ancestral de Gestión Integral del Agua
}

\author{
Sergio Martos-Rosillo(1), Antonio González-Ramón ${ }^{(1)}$, Ana Ruiz-Constán ${ }^{(1)}$, Carlos Marín-Lechado(1), \\ Carolina Guardiola-Albert ${ }^{(2)}$, Francisco Moral Martos ${ }^{(3)}$, Jorge Jódar ${ }^{(4)}$ y Antonio Pedrera Parias ${ }^{(5)}$ \\ (1) Instituto Geológico y Minero de España. Urbanización Alcázar del Genil, 4. Granada, 18006. \\ s.martos@igme.es, antonio.gonzalez@igme.es, a.ruiz@igme.es, c.marin@igme.es \\ (2) Instituto Geológico y Minero de España. C/Ríos Rosas, 23. Madrid, 28003. \\ c.guardiola@igme.es \\ (3) Universidad Pablo de Olavide de Sevilla; Carretera de Utrera, km 1. Sevilla, 41013. \\ fmormar@upo.es \\ (4) Instituto Geológico y Minero de España. C/Manuel Lasala, 44, 9². Zaragoza, 50006. \\ j.jodar@igme.es \\ (5) Instituto Geológico y Minero de España. Subdelegación de Gobierno, Plaza de España, Torre Norte. Sevilla, 41013. \\ a.pedrera@igme.es
}

\section{RESUMEN}

Sierra Nevada es la principal cadena montañosa del sur de la Península lbérica y está catalogada como Reserva de la Biosfera (1986), Parque Natural (1989) y Parque Nacional (1999). Entre sus muchas singularidades de tipo ecológico, geomorfológico y paisajístico, hay otras de tipo hidrológico e histórico-cultural, como la del manejo ancestral del agua que se realiza en la cabecera de sus ríos. Una densa red de canales excavados en la tierra, las acequias de careo, permite derivar el agua de deshielo de la cabecera de los ríos para infiltrarla en la zona alta de las laderas. El agua infiltrada en la zona de alteración de las rocas metamórficas discurre lentamente ladera abajo para alimentar a los ríos y a los manantiales que se usan para abastecimiento y regadío. Este sistema de manejo del agua, implantado desde la conquista árabo-beréber del sur de España, durante el siglo VIII, ha provocado una notable transformación del paisaje, donde las terrazas de cultivo y los pastos coexisten con ecosistemas de alto valor ecológico. En este trabajo se describe la técnica del careo en una cuenca piloto, la cuenca del río Bérchules, estudiada durante los años 2014 y 2015 por el Instituto Geológico y Minero de España. La emigración, el abandono de las tierras de cultivo y, como consecuencia, de las acequias de careo están afectando al régimen de funcionamiento de los ríos, haciendo peligrar el especial equilibrio alcanzado entre el hombre y la naturaleza en Sierra Nevada, tras muchos siglos de convivencia en armonía.

Palabras clave: Acequias de careo, Alpujarra, alta montaña, recarga artificial, rocas duras.

\section{Water management in the high mountain watersheds of the Sierra Nevada National Park (southern Spain). An example of ancestral Integrated Water Management}

\begin{abstract}
Sierra Nevada is the main mountain range in the southern Iberian Peninsula and has been catalogued as a Biosphere Reserve (1986), a Natural Park (1989) and a National Park (1999). Apart from its ecological, geomorphological and landscape singularities, there are other remarkable hydrological, historical and cultural features, such as the ancestral water management performed at the headwaters of the rivers. $A$ dense network channels excavated in the ground, the so-called acequias de careo, allows the derivation of melt water from of the river water head towards the higher zone of the hillsides, where it infiltrates. It slowly flows down
\end{abstract}


Sergio Martos-Rosillo, et al., 2019. El manejo del agua en las cuencas de alta montaña... Boletín Geológico y Minero, 130 (4): $729-742$

through the weathered zone of the metamorphic rocks, until reaching the rivers and springs used for supply and irrigation. This water management system, implemented since the Muslim conquest of southern Spain (VIII century), has led to a remarkable transformation of the landscape, where agricultural terraces and pastures coexist with ecosystems of high ecological value. This paper describes the careos water-management technique in a pilot basin, the Bérchules watershed, recently studied during 2014 and 2015 by the Geological Survey of Spain. Migration, the abandonment of cultivated lands and, consequently, of the acequias de careo are affecting the dynamics of the rivers, endangering the delicate balance reached between man and nature in the Sierra Nevada, after many centuries of harmonious coexistence.

Keywords: Acequias de careo, Alpujarra, high mountain, artificial recharge, hard rocks.

\section{Introducción}

Sierra Nevada es un macizo montañoso que forma parte de la Cordillera Bética y que se sitúa al sureste de la Península Ibérica, en las provincias de Almería y Granada, a escasa distancia del mar Mediterráneo (Figura 1). Se trata de una antiforma con orientación este-oeste, que se extiende a lo largo de $90 \mathrm{~km}$, con una anchura variable entre 15 y $40 \mathrm{~km}$. En su parte central afloran rocas metamórficas, mayoritariamente esquistos, del Complejo Nevado -Filábride, rodeados por materiales carbonatados y metapelitas del Complejo Alpujárride, ambos deformados por la tectónica alpina (Sanz de Galdeano and López-Garrido, 1998). Esta montaña cuenta con los picos más altos de la Península Ibérica, entre los que destacan el Mulhacén, con 3482 m s.n.m. y el Veleta, con 3398 m s.n.m.

Su gran altitud, su aislamiento, con respecto a otros macizos montañosos, su proximidad al continente africano y su reciente deglaciación contribuyen a que Sierra Nevada constituya una alta montaña mediterránea semiárida especialmente singular (Gómez-Ortiz et al., 2013; 2015). De hecho, esta montaña es un espacio especialmente protegido, declarado Reserva de la Biosfera en 1986, Parque Natural en 1989 y Parque Nacional en 1999. Para hacer compatible la Reserva de la Biosfera con la figura de Parque Nacional y Natural se constituyó como modelo de gestión integrada el Espacio Natural de Sierra Nevada, quedando el Parque Natural (86266 ha) como zona de amortiguación y transición respecto al área declarada Parque Nacional (85883 ha). Esta labor de conservación ha permitido que el Espacio Natural de Sierra Nevada entrase a formar parte de la Green List de la International Union for Conservation of Nature, en 2014.

Entre los principales valores ambientales de Sierra Nevada destaca su extraordinaria biodiversidad. Su diversidad vegetal es de las más importantes del Mediterráneo occidental, existiendo más de 2100 especies de plantas vasculares de las que más de 80 son endémicas (Blanca et al., 1998; Lorite et al., 2007; Brewer et al., 2002). El elevado número de ecosistemas favorece, como no, una alta variedad faunística. Entre las casi 300 especies de vertebrados, las aves son el grupo más representado con unas 200 especies. Sin embargo, Sierra Nevada es reconocida por albergar la mayor población y con mayor variabilidad genética de cabra montés de la Península Ibérica (Granados and Cano-Manuel, 2015). Hay catalogadas más de 18000 especies de invertebrados, con 300 especies exclusivas de insectos. A estos valores debemos añadir los geomorfológicos. La huella glaciar y periglaciar conformada durante las crisis climáticas cuaternarias y durante la Pequeña Edad del Hielo han plasmado su impronta en este relieve. En Sierra Nevada se desarrollaron los sistemas glaciares más meridionales de Europa. Así, por encima de los $2500 \mathrm{~m}$ de altitud destaca la presencia de formaciones glaciares y periglaciares. Hoy en día se pueden visitar numerosos circos glaciares, morrenas y glaciares rocosos con cubetas de sobreexcavación convertidas, muchas de ellas, en espectaculares lagunas de alta montaña (Castillo, 2009; Gómez-Ortiz et al., 2013).

No menos importantes que los valores ambientales son sus valores históricos y culturales. Sierra Nevada es una montaña humanizada desde hace miles de años. Existen asentamientos neolíticos, restos de las culturas de los metales, huellas del paso de las culturas fenicia, cartaginense, romana, visigoda y árabe (Martín-Civantos, 2007). Pese al importante número de culturas que han habitado Sierra Nevada, fue la cultura árabe la que más huella dejó. Durante el periodo de Al-Ándalus, entre los siglos VIII y XV, los andalusíes realizaron una notable transformación del paisaje de Sierra Nevada, en especial de su vertiente meridional. Se construyeron innumerables terrazas de cultivo, junto a las cuales se desarrollaron los principales núcleos de población. Para regar estas zonas agrícolas se construyó una densa red de acequias que derivaban el agua de los ríos. Sin embargo, el caudal de los ríos se reducía durante el estiaje, cuando más agua se necesitaba para el riego de las zonas de vega. 
Para incrementar el caudal de los ríos en verano y para mantener el caudal de los manantiales de abastecimiento, los andalusíes idearon un sistema colectivo de manejo del agua basado en el uso conjunto del agua superficial y subterránea. Este sistema de manejo del agua sigue en funcionamiento a día de hoy, con ciertas modificaciones en algunas de las cuencas de alta montaña de Sierra Nevada y constituye un ejemplo muy representativo del nuevo paradigma de la Gestión Integral del Agua (Vivas et al., 2009). En este trabajo se presenta el ancestral sistema de Gestión Integral del Agua que se realiza en algunas de las cuencas de alta montaña de Sierra Nevada y se describe su eficiencia hidrológica e hidrogeológica en la cuenca piloto del río Bérchules (Figura 1). Esta cuenca ha sido investigada recientemente por el Instituto Geológico y Minero de España con motivo de un proyecto de investigación hidrológico e hidrogeológico realizado para la Junta de Andalucía (IGME, 2015).

\section{Principales rasgos hidrogeológicos de Sierra Nevada}

En Sierra Nevada se distinguen dos grandes conjuntos de materiales acuíferos con un comportamiento claramente diferenciado (Figura 1): los acuíferos en rocas duras del Nevado-Filábride y los acuíferos carbonáticos de las Alpujarras y del Padul. En la parte central, la de mayor altitud, y ocupando un $79 \%$ de la superficie del Espacio Natural, afloran metapelitas del Complejo Nevado-Filábride. Estos afloramientos dan lugar a un extenso acuífero en rocas duras $\left(1358 \mathrm{~km}^{2}\right)$, formado por su zona de alteración superficial, a la que, en las zonas más altas de la montaña, se superponen formaciones cuaternarias, fundamentalmente de tipo glaciar y periglaciar. El citado núcleo NevadoFilábride se encuentra parcialmente rodeado, fundamentalmente al oeste y al sur, por una orla carbonática de materiales acuíferos del Complejo Alpujárride. El total de afloramientos carbonáticos alpujárrides dentro del Espacio Natural es de $220 \mathrm{~km}^{2}$, es decir un $13 \%$ de su superficie.

\section{Acuíferos en rocas duras de Sierra Nevada}

Sobre los afloramientos de rocas metamórficas de Sierra Nevada suele desarrollarse una capa de alteración permeable. Esta capa comprende una zona de alteración superficial, formada por esquistos meteori-

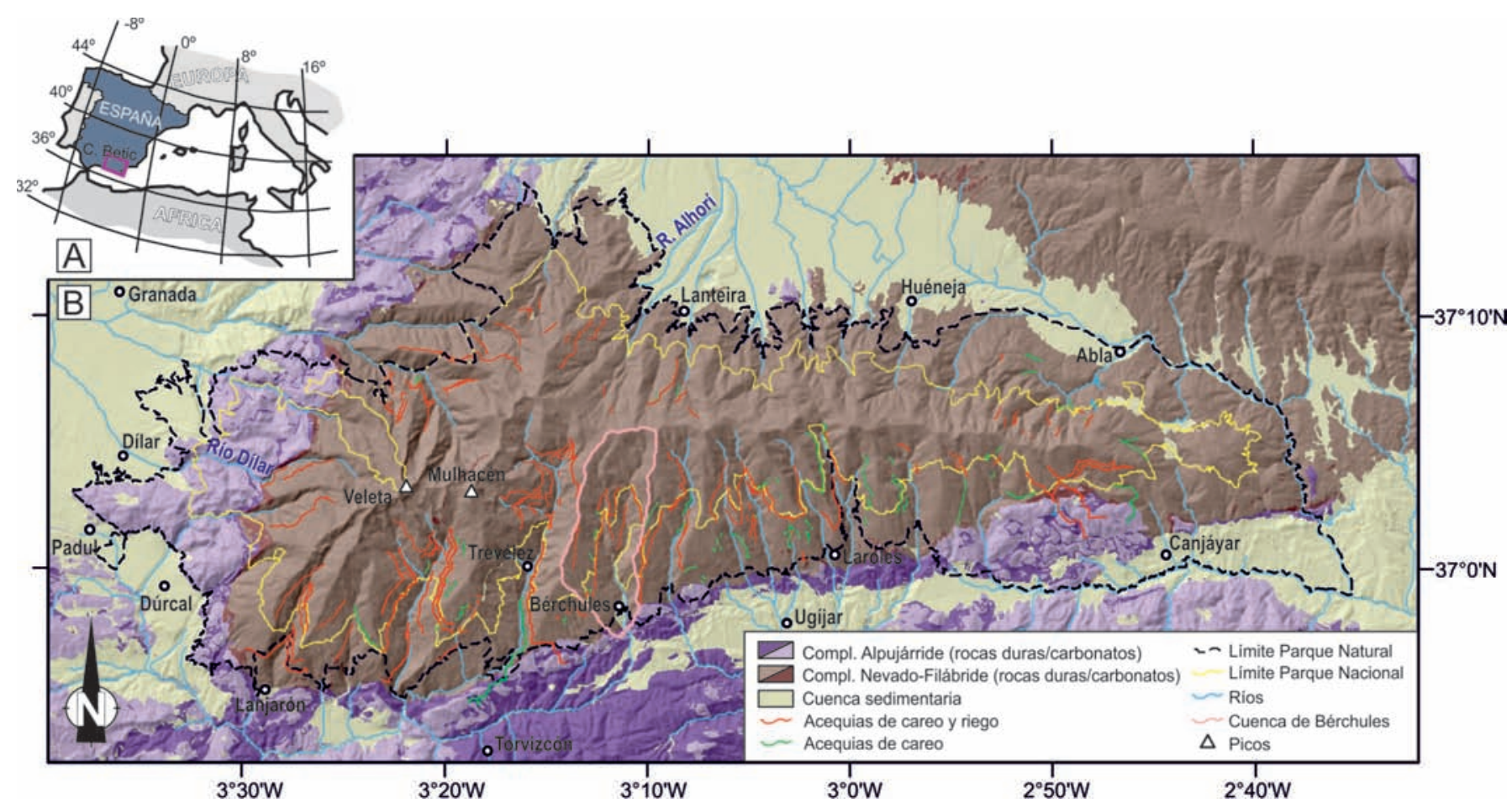

Figura 1. Mapa hidrogeológico sintético de Sierra Nevada, con los límites del Parque Natural y del Parque Nacional, de la cuenca piloto investigada en el río Bérchules y las acequias de careo y de careo/riego cartografiadas.

Figure 1. Synthetic hydrogeological map of Sierra Nevada, with the limits of the Natural Park and the National Park, the pilot basin investigated in the Bérchules River, and the mapped careo channels and the careo/irrigation channels. 
zados y disgregados, y una zona fisurada y fractura$\mathrm{da}$, que se prolonga en profundidad hasta llegar a la roca inalterada. Estas dos zonas coinciden con las conocidas como saprolite y saprock, en la terminología inglesa (UNESCO, 1985, Singhal y Gupta, 2010). Por encima de los $2500 \mathrm{~m}$ de altitud, las condiciones climáticas frías condicionan el predominio de la meteorización física por gelifracción, lo que ha permitido el desarrollo de un manto de gelifractos que, con la excepción de las zonas más escarpadas, ocupa casi toda la zona de cumbres. Otros depósitos de derrubios, de ubicación más localizada, son los canchales existentes al pie de los escarpes y los sedimentos glaciares acumulados en la cabecera de los valles más altos. Por debajo de los $2500 \mathrm{~m}$, el aumento de la temperatura determina unas condiciones favorables para los procesos de meteorización química y edafización, lo que parece producir una disminución de la permeabilidad del manto de alteración, probablemente a causa de la presencia de una mayor fracción arcillosa. Todo este conjunto de materiales configura un acuífero superficial (Figura 2), de reducido espesor (se estiman profundidades máximas de 30-50 m) pero muy extenso, dado que cubre la práctica totalidad de Sierra Nevada.

El funcionamiento hidrogeológico de este acuífero es diferente según la altitud (Castillo et al., 1996, 1999.; Castillo y Fedeli, 2002; Fedeli y Castillo, 1998; González -Ramón et al., 2015, Martos-Rosillo et al., 2017). La alta permeabilidad del manto de gelifractos, la baja pendiente de las zonas altas de Sierra Nevada, el elevado porcentaje de precipitación en forma de nieve y su lento proceso de fusión hacen que la práctica totalidad de la escorrentía que se produce en la zona de cumbres se infiltre en el acuífero. Al hacerse menor la altitud, dejan de existir sedimentos glaciares y periglaciares. El acuífero pasa a estar formado, fundamentalmente, por la capa de alteración superficial de los esquistos y aumenta el desarrollo de los suelos y de la vegetación. Se incrementa la evapotranspiración $y$, además, disminuye la precipitación media. Todos estos hechos hacen que en la franja altitudinal comprendida entre 1600 y 2000 m s.n.m. la recarga natural del acuífero sea notablemente inferior a la de las zonas altas de Sierra Nevada. Sin embargo, por debajo de los $1600 \mathrm{~m}$ de altitud, que es la altitud media de las acequias de careo (Ortiz-Moreno, 2010), la recarga vuelve a aumentar, debido tanto a los careos como a los retornos de riego (Pulido y Sbih, 1995; Martos-Rosillo et al. 2015 a y b, Martos Rosillo et al., 2017).

Fedeli y Castillo (1998) hicieron una clasificación de los distintos tipos de manantiales que existen en las zonas altas del acuífero en rocas duras de Sierra
Nevada. Esta clasificación se ha complementado en la Figura 3, habiendo definido siete tipos de surgencias en los materiales del Nevado Filábride y dos en los materiales del Alpujárride.

Los manantiales menos inerciales y de mayor caudal son los que se sitúan a mayor cota (manantiales de tipo 1, en la Figura 3), en los bordes inferiores de los cuerpos detríticos glaciares (generalmente morrenas laterales y frontales). Estos se activan durante el deshielo y pueden permanecer en funcionamiento hasta la época de nieves, aunque este hecho no es frecuente (Figura 4a). Por debajo de este tipo de manantiales, otro grupo de menor caudal y un poco más inercial, se relaciona con las inflexiones del terreno en el pie de circos glaciares y cubetas de sobreexcavación (manantiales de tipo 2, Figura 3). En estas zonas de cambio de pendiente es frecuente encontrar las lagunas de alta montaña de Sierra Nevada (Castillo, 2009) (Figura 4b). Los coeficientes de agotamiento determinados por Castillo y Fedeli (2002) en los manantiales de la cabecera de las cuencas de los ríos Genil y Monachil presentaban valores comprendidos entre 2,4 y $8 \times 10^{-2}$ días $^{-1}$. Estos resultados son indicativos de una alta permeabilidad, acorde con la

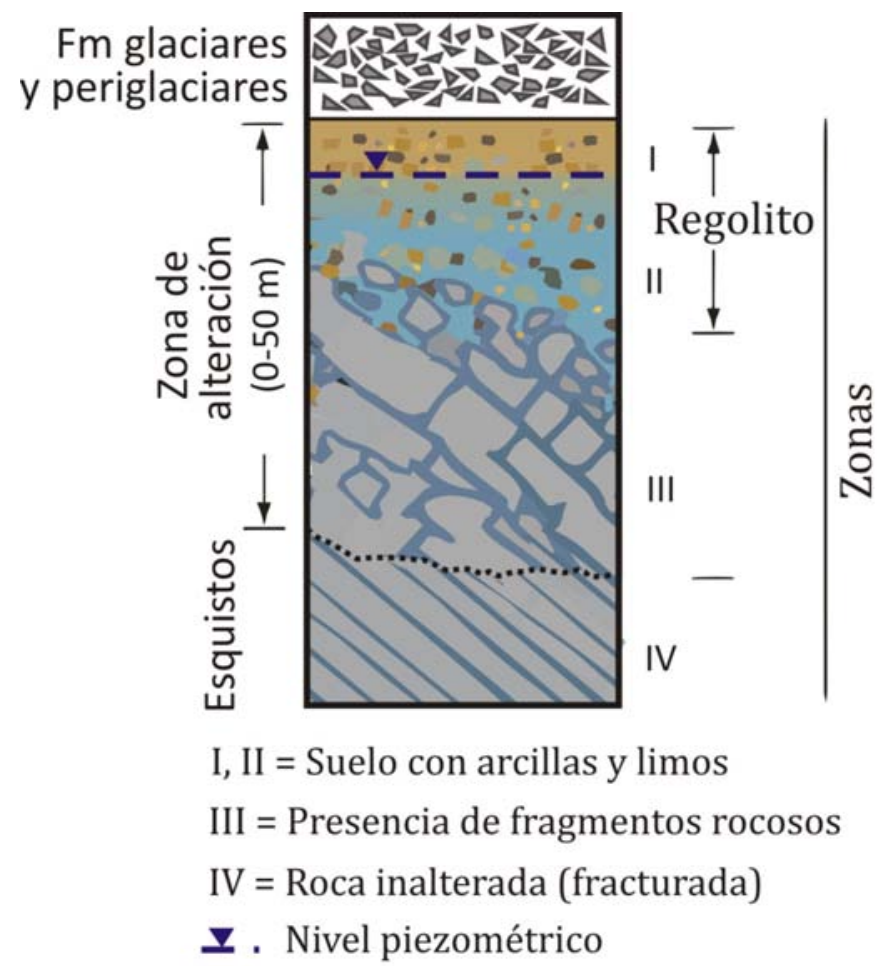

Figura 2. Columna litológica sintética del acuífero en rocas duras Nevado Filábride de Sierra Nevada.

Figure 2. Synthetic lithological column of the Nevado Filábride hard rock aquifer in Sierra Nevada. 


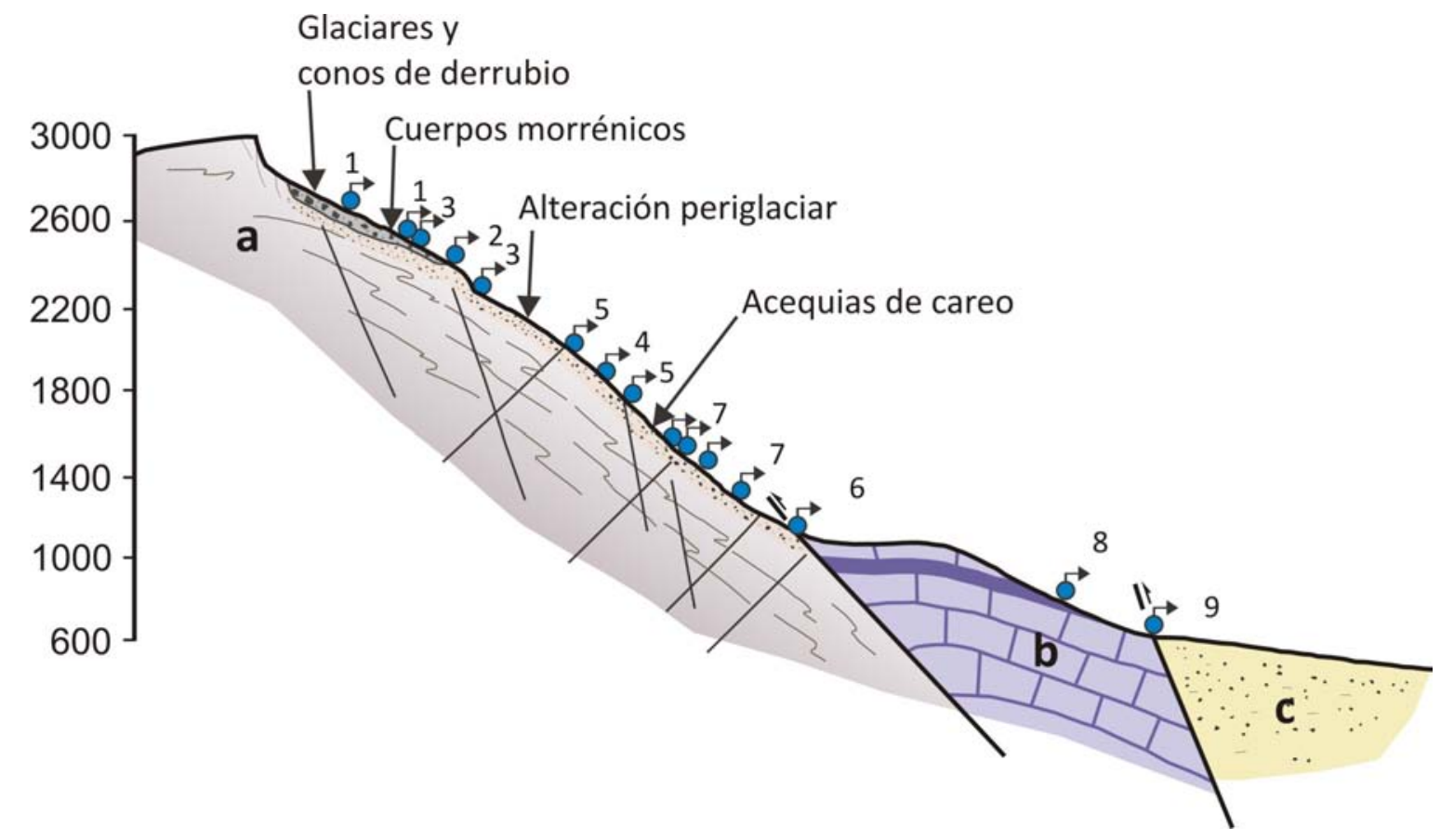

Figura 3. Esquema sintético con los distintos acuíferos y tipos de manantiales que pueden encontrarse en las laderas de Sierra Nevada. (a) Acuífero en rocas duras (b), acuífero carbonático alpujárride (c), materiales detríticos de relleno de cuencas sedimentarias (Modificado de Fedeli y Castillo, 1998).

Figure 3. Synthetic scheme with different aquifers and types of springs that can be found in the slopes of Sierra Nevada. (a) Aquifer in hard rocks (b), Alpujárride carbonate aquifer (c), detrital materials from sedimentary basins (Modified from Fedeli and Castillo, 1998).

naturaleza de los materiales glaciares y periglaciares que drenan.

Por debajo del anterior grupo de manantiales, hasta altitudes de 2000-2200 m s.n.m., aparecen numerosas zonas con una vegetación característica y con pequeñas descargas de agua subterránea, pero que suelen mantenerse desde el deshielo a la época de nieves. A estas zonas se les denomina borreguiles, lo que evidencia su tradicional uso ganadero (manantiales de tipo 3 en la Figura 3). A veces están relacionados con los lóbulos de solifluxión, formándose, también en las cabeceras de los barrancos y en zonas deprimidas de fondos de circo y/o de cambio de pendiente del terreno (Oliva et al., 2009, Fedeli and Castillo, 1998, Castillo and Fedeli, 2002). La vegetación que los coloniza está adaptada en sus zonas centrales a unas condiciones turbosas y de alta saturación en agua, mientras que los pastos son menos hidrófilos en sus bordes. En las zonas de mayor pendiente, en el extremo inferior de los borreguiles suele existir un pequeño manantial. Cuando los borreguiles se forman en zonas de pendiente suave pueden presentar manantiales o zonas de surgencia en la zona central del propio borreguil. La presencia de materiales detríticos finos y el mayor grado de cobertura vegetal hace que estos manantiales presenten una descarga lenta. Durante el estiaje, es posible avistar numerosos borreguiles que descargan sus aguas en la cabecera de los ríos (Figura 4c), permitiendo la existencia de un caudal continuo de especial interés ambiental.

Entre 1600 y 2100 m s.n.m. el número de manantiales y el caudal drenado por los mismos se reduce considerablemente. El acuífero pasa a estar formado solo por la zona de alteración de los esquistos, donde la fracción detrítica es más fina y sobre la que se desarrollan suelos con una cobertera vegetal con unas importantes exigencias hídricas (fundamentalmente coníferas, matorral, pastos y cultivos de alta montaña). Sin embargo, hasta 1700-1800 m s.n.m. se puede identificar otro grupo de manantiales relacionados con la denudación de las franjas de alteración por erosión fluvial remontante (manantiales de tipo 4 en la Figura 3). En estas áreas más bajas, la rápida incisión fluvial puede desencadenar grandes deslizamientos de roca, en la zona de ruptura de pendiente de los ríos, denominados poyos, en la terminología local, relacionados con el máximo avance glaciar y a los que se asocian manantiales (González-Ramón et al., 2015) (Figura 4d). 


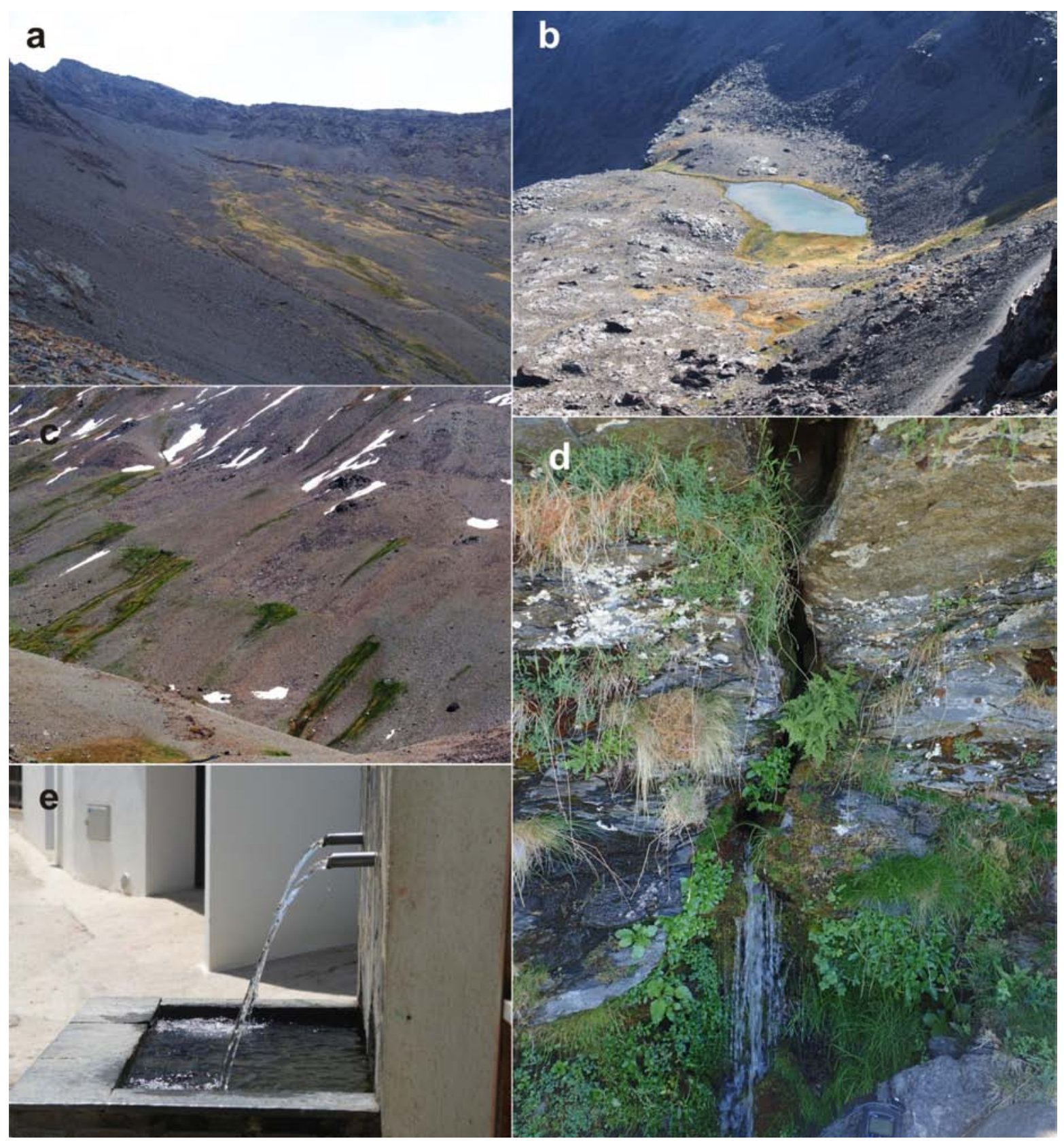

Figura 4. (a) Grupos de manantiales asociados a depósitos glaciares y periglaciares en el circo del Veleta. (b) Las descargas de agua subterránea al pie de los paredones de la Alcazaba y el Mulhacén se almacenan en la Laguna de la Mosca, (c) Borreguiles en la cabecera del río Lanjarón. (d) Manantial asociado a una fractura generada por deslizamientos de masas de esquistos en la ladera del río Bérchules. (e) Los manantiales del núcleo urbano de Bérchules mantienen su caudal en verano gracias a los careos que se realizan en las acequias.

Figure 4. (a) Groups of springs associated with glacial and periglacial deposits in the Veleta cirque. (b) The groundwater discharges at the foot of the Alcazaba and the Mulhacén peaks are stored in the Laguna de la Mosca, (c) Borreguiles at the head of the Lanjarón river. (d) Spring associated with a fracture generated by landslides of schist masses on the Bérchules river slope. (e) The springs of Bérchules town maintain their flow in summer thanks to the careo channels.

Otro tipo de manantiales, también descrito por Castillo y Fedeli (op.cit) está asociado a pequeñas descargas de aguas más mineralizadas que se producen a favor de las fracturas (manantiales de tipo 5 en la Figura 3). Estos últimos se pueden encontrar a muy distintas alturas, aumentando su frecuencia cuanto menor es la cota. En este sentido se pueden diferenciar otro tipo de manantiales asociados a fracturas más profundas (manantiales de tipo 6, Figura 3), con aguas de alta mineralización y con anomalías térmi- 
cas positivas, como la que pone en contacto a los complejos Alpujárride y Nevado-Filábrides, en el borde sur de Sierra Nevada.

Por debajo de la anterior franja altitudinal el número de manantiales vuelve a aumentar considerablemente (manantiales de tipo 7, Figura 3). Estas surgencias se ubican aguas abajo de las acequias de careo y de riego (Figura 4e), que se disponen a una media de 1600 m s.n.m. (Ortiz-Moreno, 2010). En este sentido, el mapa de distribución de manantiales realizado por González-Ramón et al. (2015) en la cuenca del río Bérchules es bastante ilustrativo (Figura 5). En esta figura se puede observar con nitidez que los mayores valores de densidad de manantiales se relacionan con la franja donde se desarrollan los borreguiles, entre 2200 y 2800 m s.n.m, y con las zonas situadas aguas abajo de las acequias, que en esta cuenca presentan una gran altitud media.

Las aguas que drenan los manantiales del acuífero en rocas duras de Sierra Nevada son, fundamentalmente, bicarbonatado cálcicas y cálcico -magnésicas, con salinidades inferiores a 300-350 mg/l y temperaturas comprendidas entre 2 y $16{ }^{\circ} \mathrm{C}$ (Castillo et al., 1996, 1999). Por su parte, las asociadas al contacto entre el Nevado Filábride y el Alpujárride en la ladera sur de Sierra Nevada son de características muy dispares. Así, en el entorno de Lanjarón existen surgencias con conductividades eléctricas de incluso 25000
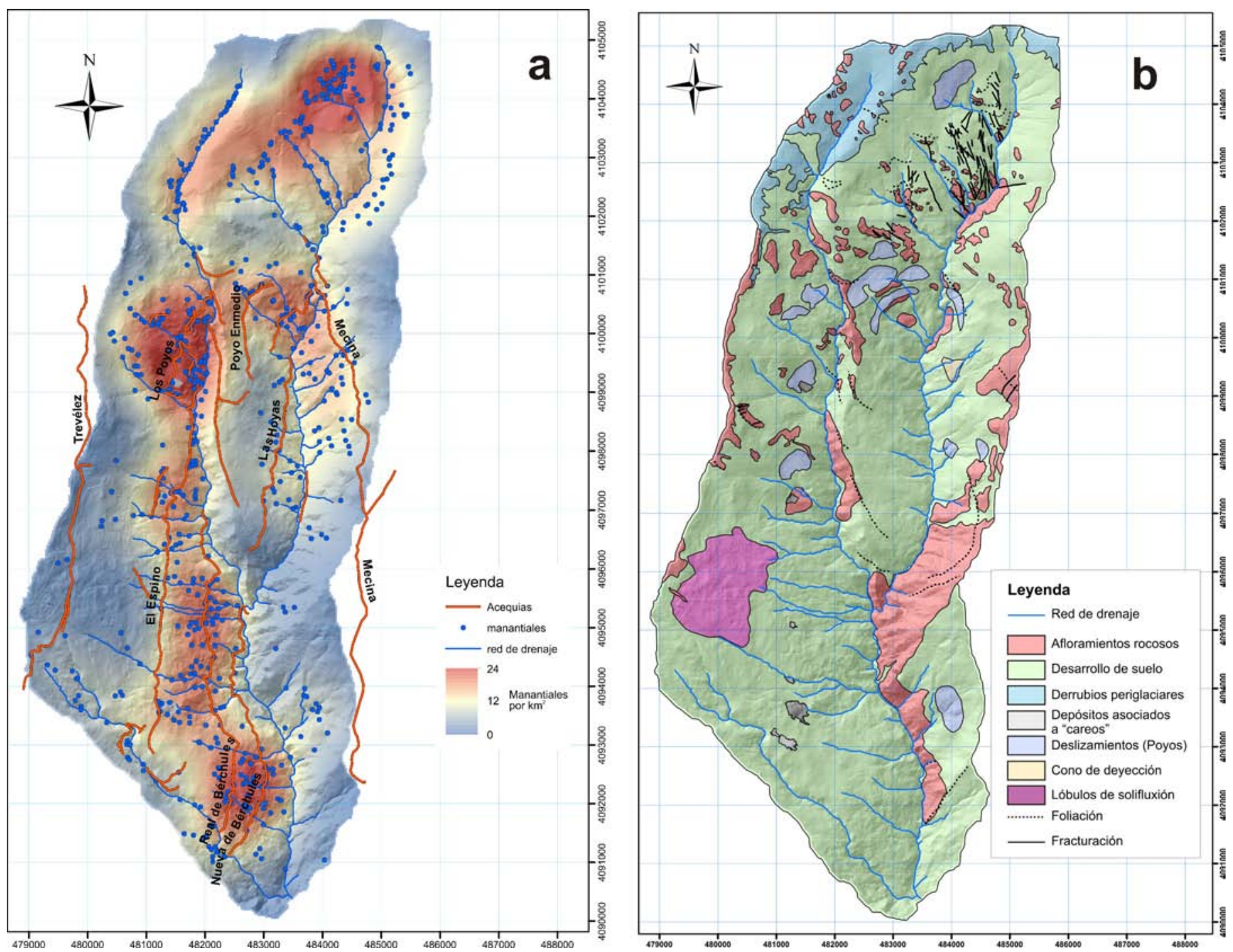

Figura 5. (a), Mapa de densidad de manantiales y situación de las principales acequias y (B), mapa de formaciones geomorfológicas cartografiadas en la cuenca del río Bérchules (Fuente: González-Ramón et al. 2015).

Figure 5. (a), Density map of springs and situation of the main acequias and (B), map of geomorphologic formations in the Bérchules watershed (From: González-Ramón et al., 2015). 
$\mu \mathrm{S} / \mathrm{cm}$, temperaturas de $25^{\circ} \mathrm{C}$, valores de $\mathrm{pH}$ menores de 6 y altas concentraciones de elementos como el hierro, manganeso, cromo, cadmio, niquel y plomo, entre otros (Castillo et al., 1999). Asociadas a otras fracturas de menor entidad, existen numerosos manantiales con aguas ferruginosas, con salinidades comprendidas entre 500 y $1000 \mathrm{mg} / \mathrm{l}$ y temperaturas máximas de $20^{\circ} \mathrm{C}$ (Castillo et al., 1996).

\section{Acuíferos carbonáticos alpujárrides}

El otro gran conjunto de acuíferos que se relacionan con Sierra Nevada está formado por carbonatos triásicos, intensamente plegados y deformados, que rodean a la sierra por el sur y especialmente por el oeste y noroeste (Pulido-Bosch, 1980; ITGE, 1999). Al oeste del macizo se encuentra el acuífero de la Sierra de Padul, con una extensión de afloramientos permeables de $135 \mathrm{~km}^{2}$ y un volumen de recursos renovables, anuales medios, estimados en $46 \mathrm{hm}^{3}$ en ITGE (1999). Al sur, los carbonatos triásicos que afloran en la margen derecha del Guadalfeo lo hacen en pequeños retazos formando acuíferos de poca importancia. Por último, en el alto Andarax, en la denominada Alpujarra almeriense, existe un conjunto notable de afloramientos de carbonatos, gracias a los cuales el río mantiene un flujo de agua permanente en su cabecera. A este grupo de acuíferos se les denomina acuíferos carbonáticos de la Alpujarra (ITGE, 1990). Su extensión se ha cifrado en $60 \mathrm{~km}^{2}$ y sus recursos medios renovables se deben aproximar, según Castillo et al. (1996), a $15 \mathrm{hm}^{3} /$ año.

La principal característica que define a estos acuíferos es su elevada compartimentación, debido a la complejidad geológica de su estructura. Esto da lugar a la presencia de multitud de manantiales que no suelen presentar grandes caudales medios (ver manantiales de tipo 8 y 9 en la Figura 3). Además, hay otros aspectos que condicionan su funcionamiento hidrogeológico, como la predominancia de mármoles, dolomías o calizas, ya que estas últimas se karstifican con mayor facilidad. En los carbonatos alpujárrides triásicos se da la circunstancia de que los mantos más profundos son los que menos grado de metamorfismo presentan, por lo que suelen estar formados mayoritariamente por calizas, al contrario de lo que ocurre en los mantos superiores. Por otra parte, los mantos más profundos afloran en el contacto con las rocas nevado-filábrides que forman el núcleo de Sierra Nevada, por esta razón suelen localizarse a mayores cotas que el resto de mantos. Esta circunstancia hace que el desarrollo de formas de karstificación superficial (dolinas y lapiaces) sea más común que en el resto de afloramientos y que el agua subterránea circule por ellos a mayor velocidad, dando lugar a manantiales con grandes variaciones de caudal a lo largo del año. Otra peculiar característica consiste en la existencia de gruesas bandas de carbonatos intensamente fracturados, hasta tal punto que la roca ha sido triturada hasta alcanzar el tamaño de grava fina y es fácilmente erosionada, de la misma forma que un sedimento detrítico suelto. A estas rocas se les Ilama "kakiritas" y adquieren un comportamiento hidrogeológico similar a los acuíferos detríticos porosos, lo que significa que la velocidad de circulación del agua es mucho menor que en un acuífero kárstico y que los manantiales asociados mantienen caudales con pequeñas variaciones anuales. Los ríos Monachil, Huenes, Dílar, Dúrcal yTorrente atraviesan estos afloramientos de carbonatos, favoreciendo la descarga de aguas subterráneas hacia sus cauces. Sin embargo, la mayor parte de la descarga del agua subterránea relacionada con los acuíferos de carbonatos triásicos de la Sierra de Padul se produce, lateralmente, hacia los acuíferos detríticos de las depresiones de Granada y Padul.

Las aguas drenadas por los carbonatos alpujárrides presentan facies bicarbonatada cálcica a cálcico magnésica, con elevadas concentraciones de sulfatos en algunos sectores. Su salinidad suele estar comprendida entre 300 y $800 \mathrm{mg} / \mathrm{l}$, y presentan un $\mathrm{pH}$ ligeramente básico (Pulido-Bosch, 1980; Castillo et al., 1996).

\section{Las acequias de careo: elementos esenciales del ancestral sistema de gestión integrada del agua en Sierra Nevada}

Para poder abastecer de agua a las poblaciones de Sierra Nevada y para regar los pastos y las terrazas de cultivo construidas en sus abruptas pendientes, fue necesario aumentar el caudal y la duración de los manantiales que surgían por encima de las poblaciones $y$, sobre todo, aumentar el caudal de los ríos durante el estiaje. Este problema se resolvió durante la época de Al-Ándalus mediante la construcción de una extensa red de canales de infiltración, excavados en el terreno sin impermeabilizar, denominados acequias de careo. Se entiende por "carear" al proceso por el que el que se recolecta el agua de escorrentía de las cabeceras de los ríos, durante la época de deshielo (marzo-junio), para infiltrarla en la zona de alteración de las rocas duras que se desarrolla en las partes altas de las laderas. Parte del agua infiltrada se recupera tiempo después, aguas abajo, disponiendo así del preciado recurso durante la época estival, 
cuando los ríos de Sierra Nevada ven reducido su caudal drásticamente tras el deshielo. En la Figura 6 se presenta un esquema conceptual del funcionamiento hidrogeológico de la margen derecha del río Bérchules, donde se realiza careo. En este caso el agua derivada por una acequia de careo (acequia del Espino) se vierte para su infiltración en una zona denominada Sima de Bérchules. El agua recargada surge, tiempo después, por numerosos manantiales que se generan en la media y baja ladera del valle, además de ser drenada por los arroyos encajados en el acuífero superficial y por el río Bérchules (Martos Rosillo et al., 2017). A mediados de junio, las acequias de careo dejan de utilizarse y otra extensa red de acequias de riego, situada a menor altitud, comienza a derivar agua de los ríos para el riego de las zonas de cultivo intensivo (Figura 7). Con este procedimiento de uso conjunto de agua superficial y subterránea se optimiza la capacidad de retención/almacenamiento del acuífero en rocas duras de Sierra Nevada.

Por su parte, en la Figura 1 se presenta un mapa con las acequias de careo cartografiadas en Sierra Nevada, donde, por el momento, se contabilizan 720 $\mathrm{km}$ de acequias de careo y de careo/riego, a los que hay que añadir unos $3000 \mathrm{~km}$ de acequias de regadío. La magnitud de estas cifras pone de manifiesto la importancia que este sistema de manejo del agua tiene en el funcionamiento de los ríos que drenan Sierra Nevada.

Con este sistema se consigue además de un beneficio social (agua de abastecimiento a la población y para riego) un indudable beneficio ambiental. La mayor parte del agua infiltrada por el careo se des- carga en los arroyos encajados en el acuífero, contribuyendo a sostener la fauna acuática y la asociada a los bosques de ribera que tapizan estos cauces. Donde se realiza recarga con las acequias de careo conviven parcelas de regadío con zonas de mayor densidad de vegetación natural, lo que da lugar a paisajes culturales, resultado de siglos de una interacción sostenible entre las comunidades campesinas y el medio. En relación con lo anterior, se quiere subrayar que el sistema de manejo del agua que se realiza en Sierra Nevada consiste, en esencia, en el mismo paradigma de gestión del agua que se anhela conseguir en los países más comprometidos con el Medio Ambiente; la Gestión Integrada del Agua (GIA). Según la definición del Global Water Partnership (2000), la GIA consiste en un proceso por el que se promueve el desarrollo coordinado y la gestión del agua, el territorio y los recursos relacionados, con el objetivo de alcanzar unos beneficios sociales, económicos y de bienestar equitativos y que no comprometan la sostenibilidad de los ecosistemas vitales (GWP, 2000).

Los beneficios aportados por las acequias de careo y sus valores, tangibles e intangibles, les están haciendo empezar a recibir cierta atención y protección desde diferentes instituciones internacionales; es el caso de la UNESCO. A pesar de esto, Sierra Nevada se enfrenta a una situación de riesgo. El envejecimiento y la reducción de la población rural, el abandono de los sistemas de regadío tradicional, las repoblaciones forestales inadecuadamente planificadas y la expansión de las zonas de regadío intensivo, auspiciadas por una inadecuada política de modernización de regadíos, están contribuyendo a reducir de

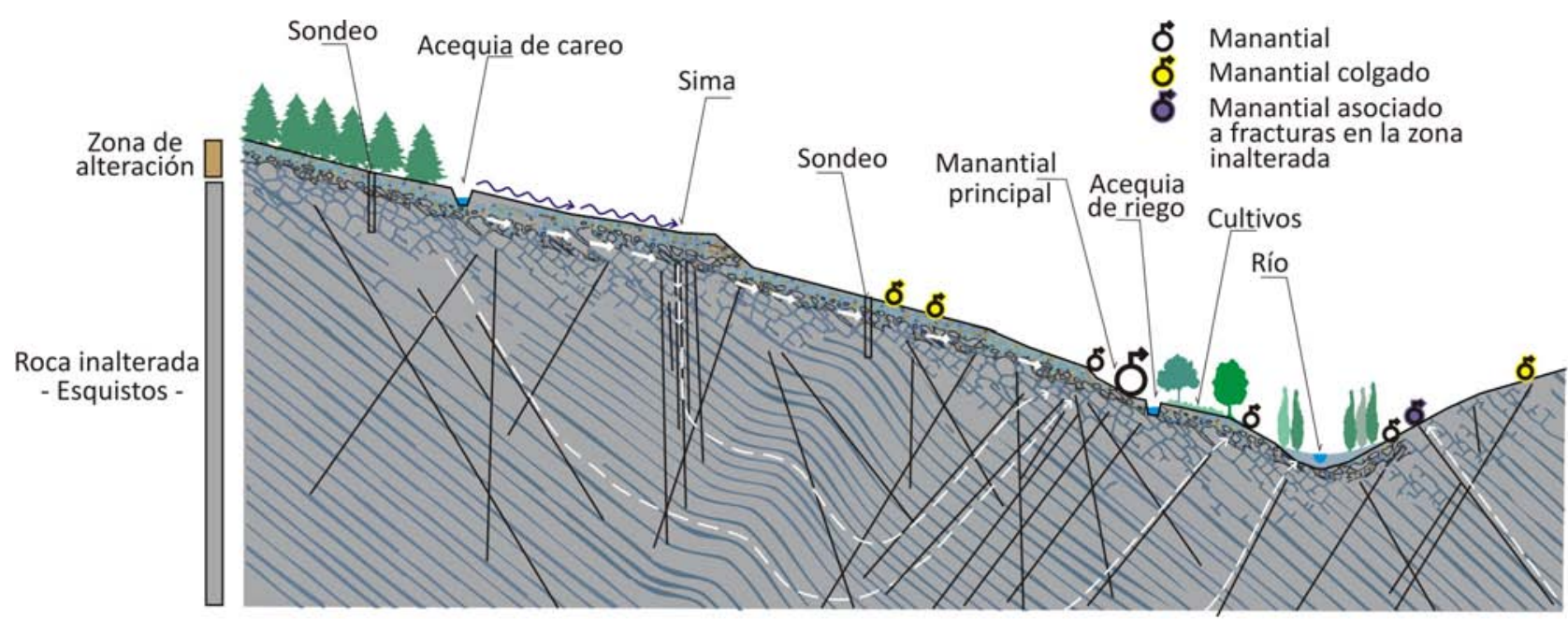

Figura 6. Esquema conceptual de funcionamiento hidrogeológico en la ladera de la margen derecha del río Bérchules. Figure 6. Hydrogeological sketch of the right bank of the Bérchules river. 


\begin{tabular}{|l|}
\hline Ene \\
\hline Feb \\
\hline Mar \\
\hline Abr \\
\hline May \\
\hline Jun \\
\hline Jul \\
\hline Ago \\
\hline Sep \\
\hline Oct \\
\hline Nov \\
\hline Dic \\
\hline
\end{tabular}
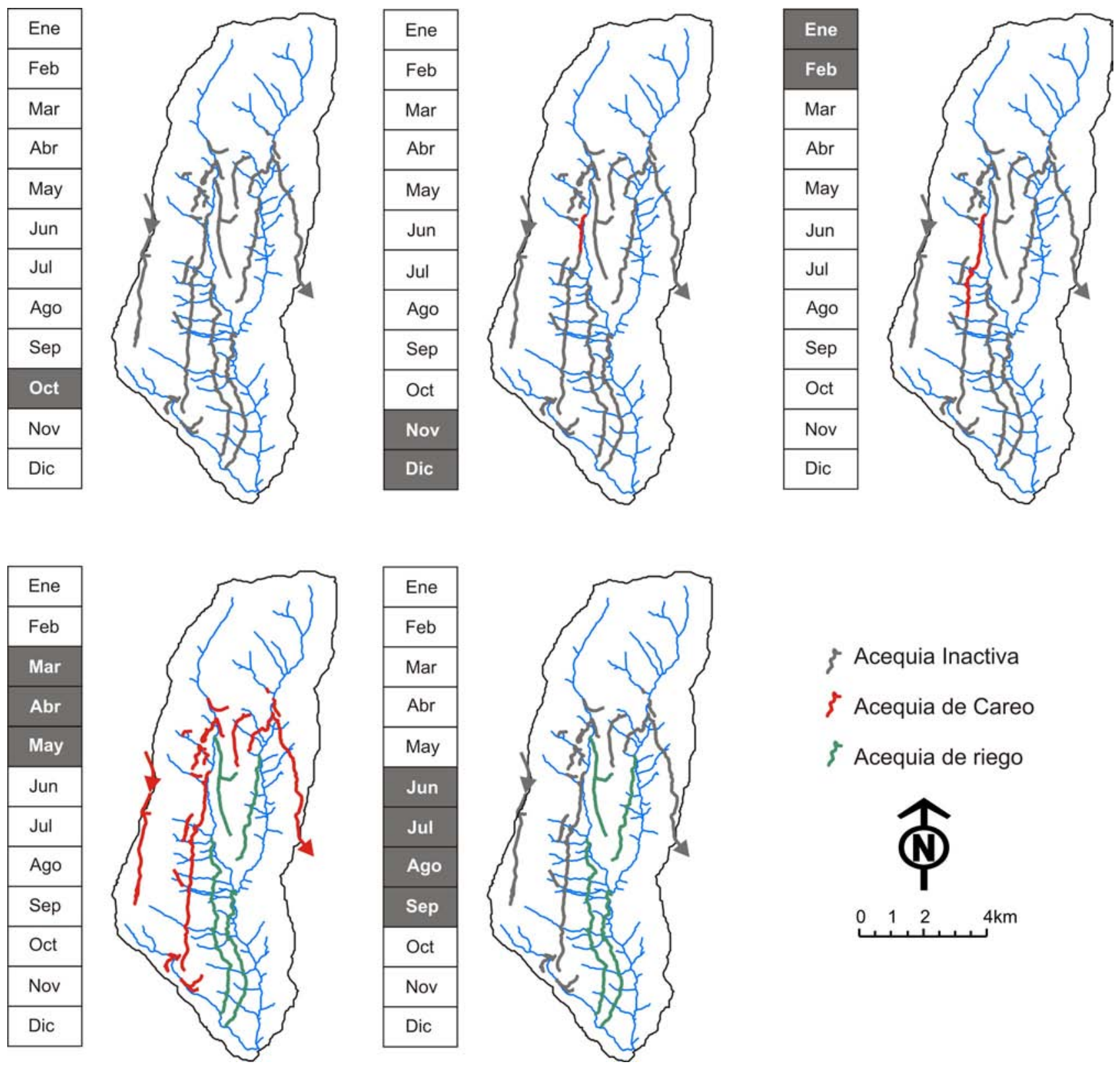

F Acequia Inactiva

5 Acequia de Careo

5 Acequia de riego

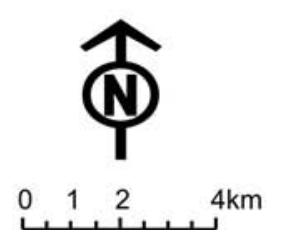

Figura 7. Esquema de funcionamiento de las acequias de riego y de careo de la cuenca del río Bérchules, durante el año hidrológico 201415 (IGME, 2015).

Figure 7. Diagram of operation of the irrigation and careo channels of the Bérchules watershed, during the 2014-15 hydrological year (IGME, 2016).

forma drástica la superficie de estos ancestrales sistemas de Gestión Integral del Agua.

\section{Repercusiones hidrológicas e hidrogeológicas del careo}

Para comprobar los efectos hidrológicos e hidrogeológicos de la técnica de careo, en la cuenca del río
Bérchules, durante el año hidrológico 2014-15 se realizó un seguimiento detallado del caudal del río (Martos-Rosillo et al., 2017) a lo largo de distintas secciones, así como de las principales acequias de careo y riego de esta cuenca hidrológica de alta montaña (Figura 8).

Los resultados del trabajo de control foronómico se sintetizan en el esquema que se presenta en la Figura 9. En el año hidrológico estudiado (2014-15) las 
aportaciones medidas en la estación de aforo fueron de $5.3 \mathrm{hm}^{3}$. Se trató de un año de tipo seco. Las aportaciones estimadas fueron muy inferiores a la media del periodo 1970-2013, que resultaron de 13.1 $\mathrm{hm}^{3} /$ año (Jódar et al., 2017). El balance hídrico de la cuenca del año 2014-2015 indica que las entradas del sistema río -acuífero $\left(7.6 \mathrm{hm}^{3} /\right.$ año$)$ se han producido por la recarga de agua (natural y artificial) en el acuífero y las salidas se han repartido entre $1.5 \mathrm{hm}^{3}$ para regadío y abastecimiento, y $1.2 \mathrm{hm}^{3}$ para su trasferencia a la cuenca del río Mecina; el resto, $5.3 \mathrm{hm}^{3}$, han discurrido superficialmente por el río Bérchules, aguas abajo de su estación de aforo. La diferencia entre las entradas y las salidas se explicaría por una disminución del volumen de agua almacenado en el acuífero o por un error de cierre del balance.

Otra evidencia de la influencia que el careo tiene en el funcionamiento hidrológico e hidrogeológico del río Bérchules se comprueba al comparar los hidrogramas de la parte alta y de la parte baja de la cuenca. En la Figura 10 se compara el hidrograma de la cabecera del río, que resulta de sumar los caudales

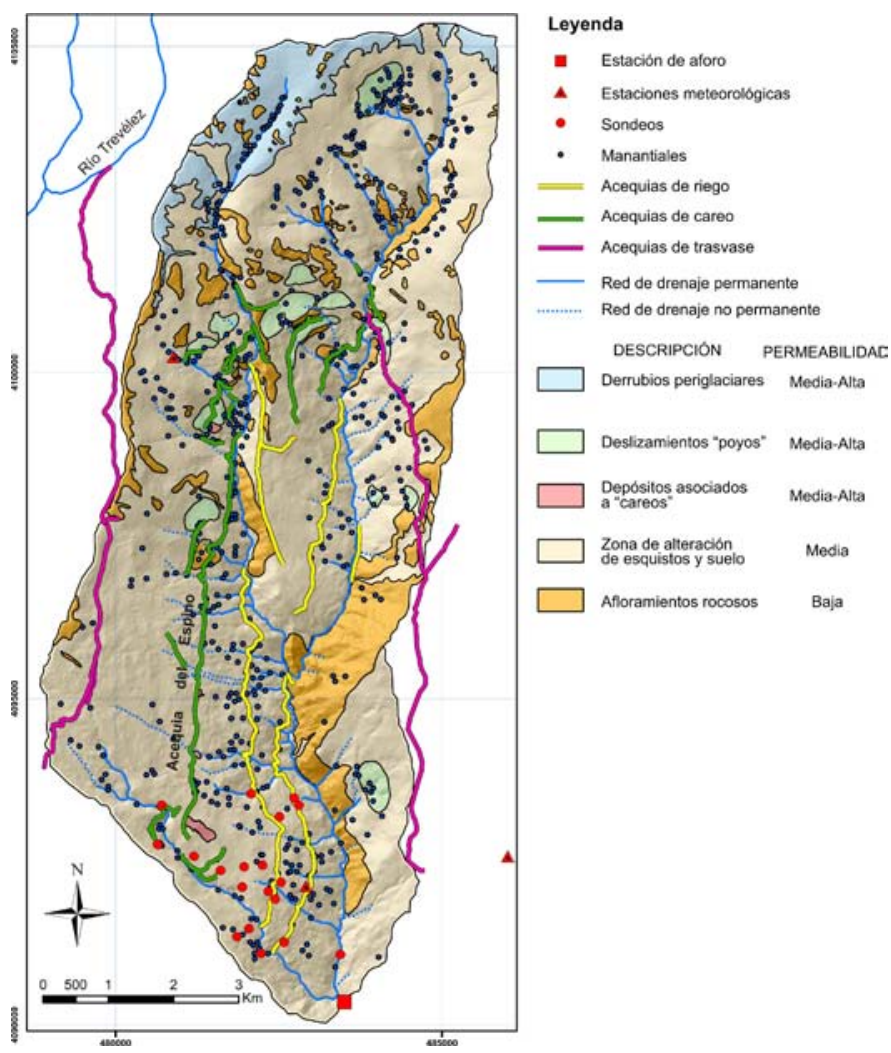

Figura 8. Mapa hidrogeológico del acuífero de Bérchules (A partir de Martos-Rosillo et al., 2015b).

Figure 8. Hydrogeological map of the Bérchules aquifer (From: Martos-Rosillo et al., 2015b).

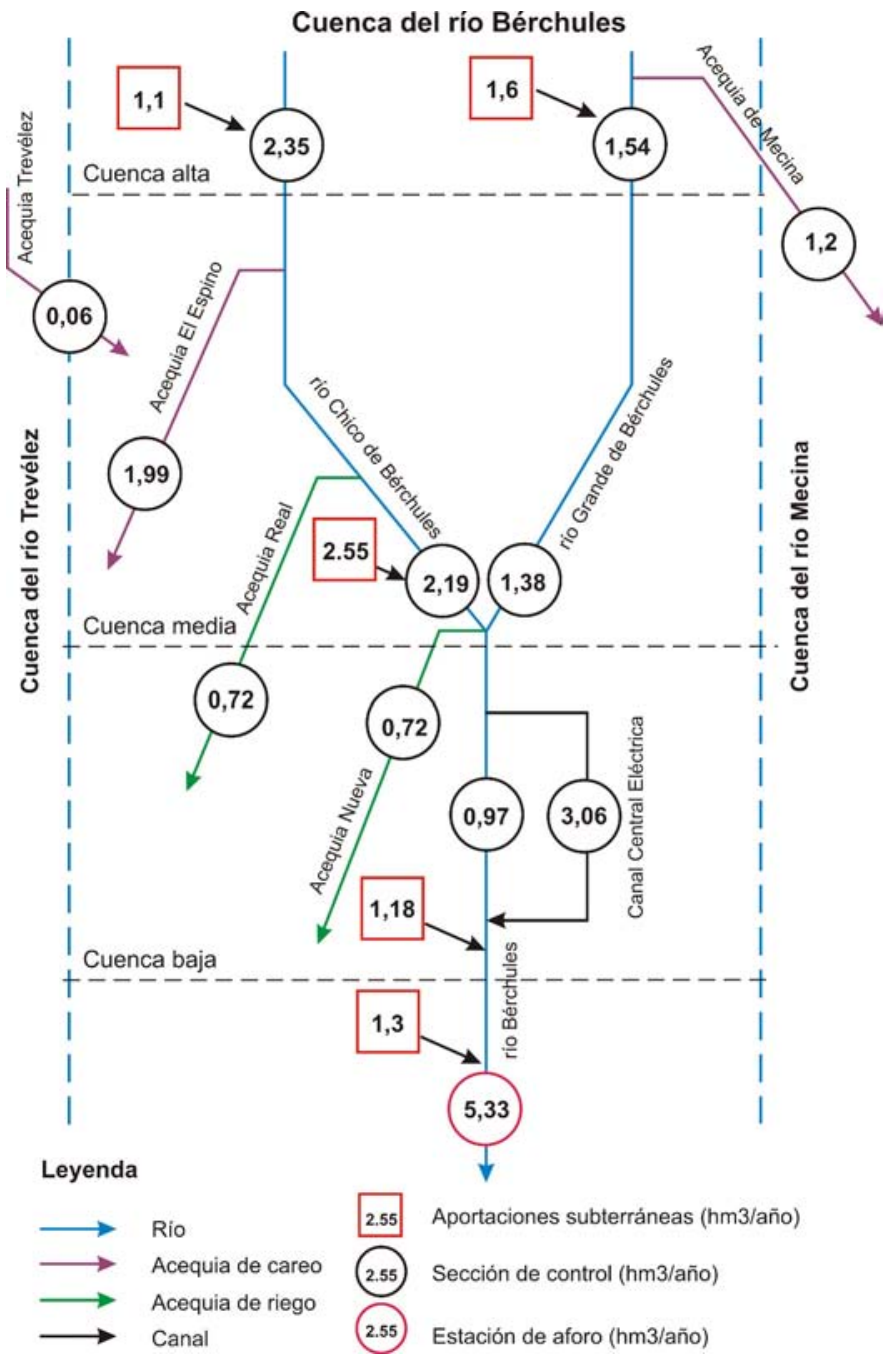

Figura 9. Esquema hidrológico del río Bérchules, con cifras de aportaciones en $\mathrm{hm}^{3}$, correspondientes al año hidrológico 2014-2015.

Figure 9. Hydrological scheme of the Bérchules watershed, with contributions in $\mathrm{hm}^{3}$, corresponding to the hydrological year 20142015.

medidos aguas arriba de las principales acequias de careo y de compararlos con el hidrograma de la estación de aforo, en la parte baja de la cuenca. En la cabecera, el hidrograma es claramente nival, con un caudal de base muy constante que se ve notablemente incrementado durante la época de deshielo. En la estación de aforo situada en la parte baja de la cuenca, el hidrograma es muy inercial, prácticamente plano durante todo el año hidrológico, pero con un rápido agotamiento relacionado con el inicio de la época de riego.

En relación con lo anterior, en la Figura 11 se compara el hidrograma medio del río Bérchules con el de otros dos ríos de Sierra Nevada donde no se realiza 


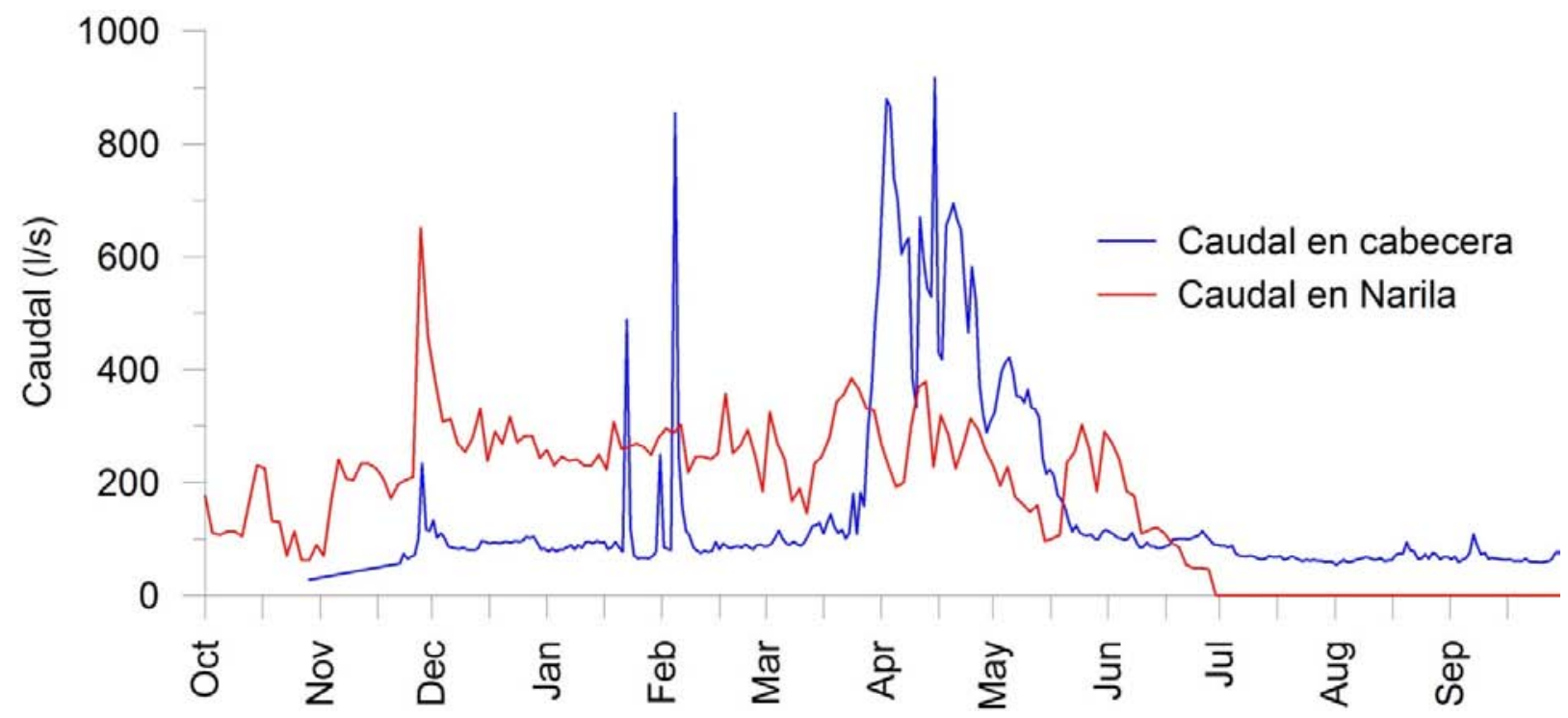

Figura 10. Hidrograma de los tributarios del Bérchules a 2000 m s.n.m. (suma de los caudales medidos en el río Chico, el río Grande y en la acequia de Mecina) frente al hidrograma medido en la estación de aforo (año hidrológico 2014-2015).

Figure 10. Hydrograph of the Bérchules tributaries at 2,000 m s.n.m. (sum of the flows measured in the Chico river, the Grande river and the Mecina irrigation canal) versus the hydrograph measured at the gauging station (hydrological year 2014-2015).

careo o donde éste es de poca entidad. Para comparar los hidrogramas, los datos de caudal se han transformado en unidades de $\mathrm{mm} / \mathrm{d}$ ía, dividiendo las aportaciones por las correspondientes superficies de cada cuenca de recepción. Las cuencas de los tres ríos son muy parecidas, con similares características fisiográficas. En el río Dílar hay varias acequias de careo abandonadas y en el Alhorí hay dos acequias de careo con un uso testimonial. Como se puede comprobar en la figura, la diferencia entre el caudal máximo de deshielo y el caudal de invierno es mayor en los ríos donde no se hace careo. La derivación del agua durante el deshielo por las acequias de careo reduce la entidad del pico nival del hidrograma en las estaciones de aforo situadas aguas abajo de las tomas de las acequias e incrementa la componente

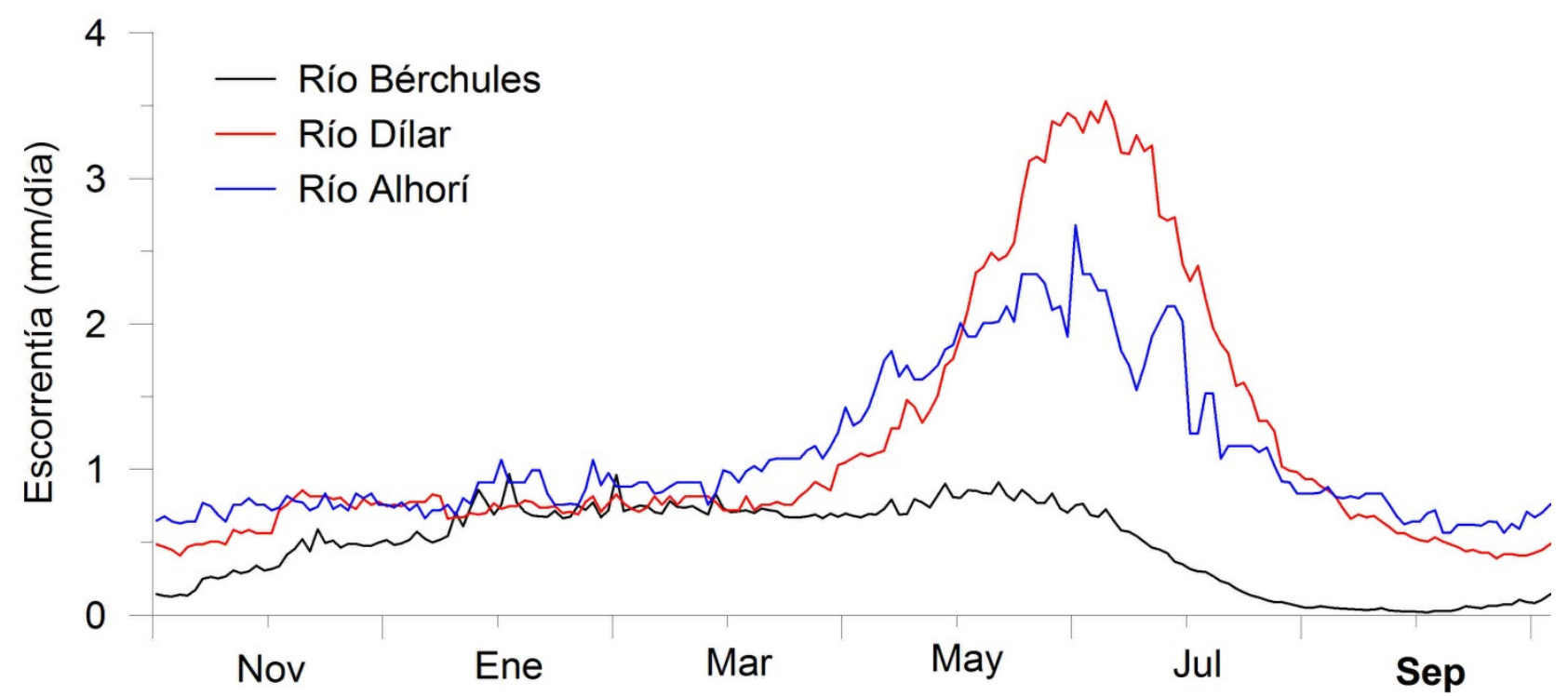

Figura 11. Hidrogramas medios de los ríos Bérchules (periodo 1970-2013), Alhorí (periodo 1994-2013) y Dílar (periodo 1970-2013). Figure 11. Average hydrograph of the Bérchules (1970-2013), Alhorí (1994-2013) and Dílar (1970-2013) rivers. 
subterránea de los hidrogramas por la recarga artificial realizada en los acuíferos. El agua surge posteriormente en estiaje para ser aprovechada en el regadío y el abastecimiento de la población local. Hay que destacar, en el caso del río Bérchules, que el caudal de estiaje se reduce de forma drástica desde mediados junio hasta octubre, debido a que en esta cuenca las principales acequias de riego se ubican aguas arriba de la estación de aforo. Situación que no se produce en el caso de las otras dos cuencas.

\section{Conclusiones}

El manejo ancestral del agua que se realiza en Sierra Nevada mediante el sistema de uso conjunto con aguas superficiales y subterráneas, en el que las acequias de careo juegan un papel fundamental, provoca un incremento de la componente subterránea en el hidrograma y modifica sustancialmente su respuesta hidrológica, haciéndola más inercial. En la cuenca piloto investigada, la cuenca del río Bérchules, los hidrogramas de la cabecera del río, claramente nivales, son muy diferentes a los registrados en la estación de aforo, situada aguas abajo. El agua de deshielo es derivada fundamentalmente para su recarga en el acuífero. Otra parte importante es utilizada para riego de pastos y de otras zonas regables. Estas actuaciones hacen que el régimen de caudales del río en la parte baja de la cuenca sea el de un río con un régimen de caudales muy inercial, con una alta componente subterránea.

De igual forma, la recarga mediante las acequias de careo en la cuenca del río Bérchules hace que aguas abajo de las acequias se mantenga un manto de vegetación con unas exigencias hídricas mucho mayores a las que se dan, de forma natural, en otras zonas del sur de Sierra Nevada. Asimismo, el careo incrementa el caudal de estiaje del río Bérchules y de los manantiales situados aguas abajo, en consecuencia su abandono implicaría una notable disminución de la aportación al río y a las citadas surgencias durante los periodos secos.

Por último, se quiere subrayar que esta técnica de manejo del agua es un ejemplo de enorme capacidad de resiliencia en términos ambientales y sociales. Las zonas de regadío tradicionales de Sierra Nevada, que se mantienen desde de la Edad Media, han superado los cambios climáticos y los drásticos cambios sociales ocurridos durante, al menos, los cinco últimos siglos, por lo que constituyen una herramienta de adaptación al Cambio Climático que permite retrasar los picos de los hidrogramas y aumentar la componente subterránea de los ríos y, por tanto su caudal de base en los periodos secos.
La emigración, el abandono de las tierras de cultivo y, como consecuencia, el de las acequias de careo están afectando al régimen de funcionamiento de los ríos, haciendo peligrar el especial equilibrio alcanzado entre el ser humano y Sierra Nevada, tras muchos siglos de convivencia en armonía. Se considera, por tanto, necesario acometer las actuaciones que permitan mantener este ejemplar sistema de gestión del agua, heredado de nuestros antepasados.

\section{Agradecimientos}

Parte del presente trabajo se encuadra dentro de los resultados del Servicio de Investigación que el IGME ha realizado a la Agencia de Medio Ambiente y Agua de la Junta de Andalucía, y constituye una contribución al nuevo ciclo de Planificación Hidrológica 20162021 de las cuencas intracomunitarias y al Grupo de Investigación RNM-126 de la Junta de Andalucía. Agradecemos la especial ayuda prestada por la Comunidad de Regantes de Bérchules. Asimismo, se quiere agradecer la gran colaboración de Francisco Javier Sánchez Gutiérrez e Ignacio Henares Civantos del Parque Nacional de Sierra Nevada. Este trabajo constituye una contribución a la Red CYTED (419RT0577): Siembra y Cosecha del Agua en Áreas Naturales Protegidas.

\section{Referencias}

Blanca, G., Cueto, M., Martínez-Lirola, M. J. and MoleroMesa, J. 1998. Threatened vascular flora of Sierra Nevada (Southern Spain). Biological Conservation, 85, 269-285.

Brewer, S., Cheddadi, R., De Beaulieu, J. L. and Reille, M. 2002. The spread of deciduous Quercus throughout Europe since the last glacial period. Forest Ecology and Management, 156, 27-48.

Castillo, A. 2009. Lagunas de Sierra Nevada. Todas las lagunas, valle a valle. Universidad de Granada, Granada, 317 pp.

Castillo, A. and Fedeli. B. 2002. Algunas pautas del comportamiento hidrogeológico de rocas duras afectadas por el glaciarismo y periglaciarismo en Sierra Nevada. Geogaceta, 32, 189-191.

Castillo, A., Cruz-Sanjulián, J.J. and Benavente, J. 1999. Aguas de Sierra Nevada; Aguas de Lanjarón. In: Lanjarón, paisajes del agua. Balneario de Lanjarón, Granada, 35-64.

Castillo, A., del Valle, M., Rubio-Campos, J.C. and Fernández-Rubio, R. 1996. Síntesis hidrogeológica del macizo de Sierra Nevada (Granada y Almería). In: $1^{a}$ Conferencia Internacional de Sierra Nevada, I, 389-417.

Fedeli, B. and Castillo, A. 1998. Condiciones de surgencia en una cuenca esquistosa de alta montaña (Sierra Nevada; Granada, España). Geogaceta, 23, 47-50 pp. 
Gómez-Ortiz, A., Oliva, M. and Salvador, F. 2013. The environmental protection of landscapes in the high semiarid Mediterranean mountain of Sierra Nevada National Park (Spain): Historical evolution and future perspectives. Applied Geography, 42, 227-239.

Gómez-Ortiz, A., Oliva, M., Palacios, D., Salvador-Franch, F, Vázquez-Selem, L., Salvá-Catarineu, M. and De Andrés, N. 2015. The deglaciation of Sierra Nevada (Spain). Synthesis of the knowledge and new contributions. Cuadernos de Investigación Geográfica, 41(2), 409-426 pp.

González-Ramón, A., Moral-Martos, F., Marín-Lechado, C., Martos-Rosillo, S., Pedrera, A. Ruiz-Constán, A. and Durán Valsero, J.J. 2015. Factores geomorfológicos condicionantes de la hidrogeología de la cuenca alta del río Bérchules (Sierra Nevada, Granada). In: B. Andreo Navarro et al. (eds). El Agua en Andalucía. El agua clave medioambiental y socioeconómica. IGME, 1, 283-294.

Granados, J.E. and Cano-Manuel, F.J. 2015. Demografía de poblaciones de ungulados silvestres y prevalencia de enfermedades. En: Zamora, R. et al. (eds). La huella del Cambio Global en Sierra Nevada: Retos para la conservación. Junta de Andalucía, 113-117.

GWP, 2000. Integrated Water Resources Management. [Online] TAC Background Paper. Report number: 4. GWP, Stockholm, Sweden. Available from: www.gwpforum. org/gwp/library/Tacno4.pdf [Accessed April 2013].

IGME, 2015. Investigación hidrogeológica de acuíferos de alta montaña sometidos a uso intensivo del agua subterránea. Cabecera del río Bérchules (Sierra Nevada, Granada). Centro de documentación del IGME, Madrid, 139 pp.

ITGE, 1990. Atlas hidrogeológico de la provincia de Granada. Diputación de Granada-ITGE, Granada, 107 pp.

ITGE, 1999. Plan de integración de los recursos hídricos subterráneos en los sistemas de abastecimiento público de Andalucía. Sectores acuíferos de Padul-La Peza y Albuñuelas. Centro de documentación del IGME, Madrid.

Jódar, J., Cabrera, J. A., Martos-Rosillo, S., Ruiz-Constán, A., González-Ramón, A., Lambán, L. J., Herrera, C. and Custodio, E. 2017. Groundwater discharge in high-mountain watersheds: A valuable resource for downstream semi-arid zones. The case of the Bérchules River in Sierra Nevada (Southern Spain). Science of the Total Environment, 593, 760-772.

Lorite, J., Ruiz-Girela, M. and Castro, J. 2007. Patterns of seed germination in Mediterranean mountains; study on 37 endemic or rare species from Sierra Nevada, SE Spain. Candollea, 62 (1), 5-16.

Martin Civantos, J. M. 2007. Poblamiento y territorio medieval en el Zenete (Granada). Universidad de Granada.

Martos-Rosillo, S., González-Ramón, A., Marín-Lechado, C, Cabrera, J.A. Guardiola-Albert, C., Jodar, J., Navarrete, E, Ruiz-Constán, A. Moral, F., Pedrera, A. Navas, R.,
López, M. and Durán, J.J. 2017. Las acequias de careo de Sierra Nevada (Sur de España), un sistema de recarga ancestral en acuíferos de alta montaña. In: Óscar Escolero, Carlos Gutiérrez y Edgar Mendoza (eds) Manejo de la recarga de acuíferos, 527-563.

Martos-Rosillo, S., González-Ramón, A., RodríguezRodríguez, F., Marín-Lechado, C., Guardiola-Albert, C., Durán Valsero, J.J., Fernández-Ruíz, L., NavarreteMazariegos, E., López-Rodríguez, M. Fernández, M., Rodríguez-Rodríguez, M., Bruque, J.M. Ruiz-Constán, A. and Pedrera, A. 2015. ¿Tiene interés hidrológico preservar las acequias de careo de Sierra Nevada? El caso de la acequia de careo de El Espino (río Bérchules, Granada). In: Andreo Navarro, B et al. (eds). El Agua en Andalucía. El agua clave medioambiental y socioeconómica. IGME, 2, 925-936,

Martos-Rosillo, S., Guardiola-Albert, C., Marín-Lechado, C., González-Ramón, A. Villagómez, B., Pelegrina, M., Fernández-Ruíz, L., Durán Valsero, J.J., NavarreteMazariegos, E., López-Rodríguez, M., Pedrera, A., RuizConstán, A. and Cabrera, J.A. 2015. Caracterización hidrogeológica y evaluación de la recarga de un acuífero de alta montaña desarrollado en rocas duras, cuenca del río Bérchules, Sierra Nevada, Granada. In: Andreo Navarro et al. (eds). El Agua en Andalucía. El agua clave medioambiental y socioeconómica. IGME, 1, 623-634.

Oliva, M., Gómez-Ortiz, A., Schulte, L. and Salvador, F. 2009. Procesos periglaciares actuales en Sierra Nevada. Distribución y morfometría de los lóbulos de solifluxión. Nimbus, 23-24, 133-148.

Ortiz-Moreno, E. 2010. Actualización, digitalización y georreferenciación de la red de acequias de careo en el Espacio Natural Protegido de Sierra Nevada. TRAGSATEC-Junta de Andalucía, 131 pp.

Pulido-Bosch, 1980. Aportación al conocimiento de la hidrogeología de los alpujárrides y sus bordes en el extremo occidental de Sierra Nevada. Universidad de GranadaFundación Juan March, 123, 51 pp.

Pulido-Bosh, A. and Sbih, Y. 1995. Centuries of artificial recharge on the southern edge of the Sierra Nevada (Granada, Spain). Environmental Geology, 26, 57-63.

Sanz de Galdeano, C. and López-Garrido, A. C. 1998. Nature and impact of the neotectonic deformation in the western Sierra Nevada (Spain), Geomorphology, 30, 259-273.

Singhal, BBS and Gupta, RP. 2010. Applied Hydrogeology of Fractures Rocks. Second Edition, Springer, 408 pp

UNESCO. 1985. Aguas subterráneas en rocas duras. UNESCO, Paris. 300 pp.

Vivas, G., Gómez-Landesa, E., Mateos, L. and Giráldez, J.V. 2009. Integrated Water Management in an ancestral water scheme in a mountainous area of southern Spain. In: World Environmental Water Resources Congress. Kansas City, Missouri, Estados Unidos, 9 pp.

Recibido: julio 2018

Revisado: septiembre 2018

Aceptado: febrero 2019

Publicado: diciembre 2019 